\title{
Editorial
}

\section{Nation Branding: Issues, Insights and Impacts}

Corporate Reputation Review (2013) 16, 5-6. doi:10.1057/crr.2012.21

We are honoured to present this special issue of Corporate Reputation Review devoted to the increasingly studied field of nation branding. This special issue is intended to contribute to the ongoing production of high-quality academic research in the nation branding domain. It is interesting to note that several emerging issues have been investigated by researchers in this field. The notion of nation brand personality has been examined by three papers published in this issue. Aspects of co-branding, indigenous identity and country image have also emerged as areas of interests by academics around the world. In this special issue, we have also unfolded insights and impacts into areas such as, leadership, mega-events, government competences, tourism and media.

As stated above, the concept of nation brand personality recurs within this special issue. The approach to this topic adopted by Kim, Shim and Dinnie sets out to identify the key dimensions of nation brand personality, examining perceived traits of nation brands including country of origin for products and services, and country for tourism, investment and residence. In a nine-country study, the authors tested variables exerting an influence on nation brand personality and identified the following five core dimensions of nation brand personality: leadership, excitement, sophistication, tradition and peacefulness. The authors conclude that a fundamental challenge to nation brand managers lies in the identification and selection of relevant personality traits according to the dimension of the nation brand under consideration.
Heslop, Nadeau, O'Reilly and Armenakyan address the issue of co-branding, another concept that is well established in the mainstream branding literature, yet less familiar in the context of the branding of nations. The authors do this in terms of the reputational impacts that flow between megaevents and the countries that host them. Specifically, two Olympic events (Beijing 2008 and Vancouver 2010) are examined. The study's analysis of variance and regression model results indicate differing reputational impacts for the two events. Whereas the results indicate that the Beijing Olympics were not successful in reputation and image enhancement of either the Olympics brand or China, the Canadian mega-event outcomes were positive for both partners. The authors conclude their paper with a discussion of implications for host locations as well as for the mega-event organizers and their sponsors.

Song and Sung focus their paper on the antecedents of nation brand personality, conducting a principal components analysis to determine the primary antecedents of nation brand personality. The authors go on to conduct a series of regression analyses to investigate the relationships between the identified antecedents and the nation brand personality dimensions. Based on a sample of 304 US college students, the results show that government competences, natural features and pop culture are crucial antecedents in nation branding.

Rojas-Méndez, Papadopoulos and Murphy provide a significant advance in the theoretical
Corporate Reputation Review Vol. 16 , No. 1, pp. 5-6 (C) 2013 Macmillan Publishers Ltd. 1363-3589 
foundations of the nation branding literature through their empirically derived and tested quantitative approach, with substantial sample sizes in the main part of the study, to measuring and positioning nation brands. Their study is based on extensive exploratory and descriptive studies carried out to identify a relevant set of personality traits that are directly applicable to nations. The study contributes a carefully developed scale that appears to work well in at least one market and in response to two different country stimuli. The authors conclude that it is possible that the 209-trait scale developed in their study may be used in other countries as well.

Pomering examine the role of indigenous identity in the nation brand. They do this by analysing a recent tourism campaign for
Australia, making observations about indigenous Australian identity in relation to the broader national identity, and placing this discussion in the context of recent international tourist arrival trends. The study concludes by examining nation brand from a marketing communications perspective where exaggerated identity claims are argued to undermine perceived brand image.

The guest editors would like to express their deep gratitude to all authors who submitted papers to this special issue and also to the reviewers whose generous time commitment is much appreciated.

\section{T.C. Melewar Suraksha Gupta Keith Dinnie}

